\title{
A Case of Recurrent Malignant Proliferating Trichilemmal Tumour Occurring in an Unusual Site
}

\author{
Meghashree $V^{1}$, Lovely George ${ }^{2}$, Kuladeepa Ananda Vaidya $K^{3}$, Safeena \\ Amber $^{4}$, Aashish Sharma ${ }^{5}$, Nigi Ross Philip ${ }^{6}$, Sukesh $^{7}$, \& Farhana Zakaria ${ }^{8}$ \\ Department of Pathology, Srinivas Institute of Medical Sciences \& Research Centre, Mukka, India \\ E-mail: lovegeorge123@gmail.com
}

Area/Section: Medical Sciences.

Type of the Paper: Medical Case Report.

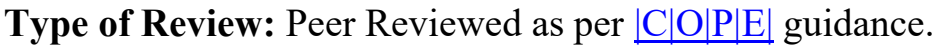

Indexed in: OpenAIRE.

DOI: http://doi.org/10.5281/zenodo.3934423.

Google Scholar Citation: $\underline{\text { IJHSP }}$

\section{How to Cite this Paper:}

Meghashree V., George, Lovely, Kuladeepa Ananda Vaidya K., Amber Safeena, Sharma Aashish, Philip Nigi Ross, Sukesh, \& Zakaria Farhana. (2020). A Case of Recurrent Malignant Proliferating Trichilemmal Tumour Occurring in an Unusual Site. International Journal of Health Sciences and Pharmacy (IJHSP), 4(1), 57-63.

DOI: http://doi.org/10.5281/zenodo.3934423.

International Journal of Health Sciences and Pharmacy (IJHSP)

A Refereed International Journal of Srinivas University, India.

(C) With Authors.

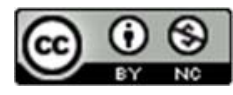

This work is licensed under a Creative Commons Attribution Non-Commercial 4.0 International License subject to proper citation to the publication source of the work.

Disclaimer: The scholarly papers as reviewed and published by the Srinivas Publications (S.P.), India are the views and opinions of their respective authors and are not the views or opinions of the SP. The SP disclaims of any harm or loss caused due to the published content to any party. 


\title{
A Case of Recurrent Malignant Proliferating Trichilemmal Tumour Occurring in an Unusual Site
}

\author{
Meghashree V. ${ }^{1}$, Lovely George ${ }^{2}$, Kuladeepa Ananda Vaidya K. ${ }^{3}$, Safeena Amber ${ }^{4}$, Aashish \\ Sharma $^{5}$, Nigi Ross Philip ${ }^{6}$, Sukesh $^{7}$, \& Farhana Zakaria ${ }^{8}$ \\ Department of Pathology, Srinivas Institute of Medical Sciences \& Research Centre, Mukka, India \\ E-mail: lovegeorge123@gmail.com
}

\begin{abstract}
Trichilemmal tumours are the tumours derived from the hair follicles. Malignant counterpart of these tumours is rarely encountered when compared to the benign ones. We present a case of recurrent malignant proliferating trichilemmal tumour in an elderly male.
\end{abstract}

Keywords: Trichilemmal, Recurrent, Pilar, Abrupt keratinization.

\section{INTRODUCTION :}

Cutaneous tumours derived from the outer root sheath of hair follicles, which show trichilemmal keratinisation (abrupt keratinisation) are trichilemmal cysts, proliferating trichilemmal cysts and malignant proliferating trichilemmal tumour. Amongst these trichilemmal lesions, malignant proliferating trichilemmal tumour is the rarest. Wilson-Jones in 1966 first recognized trichilemmal tumour as an entity that had the histologic capacity to simulate squamous cell carcinoma [1]. We report a rare case of malignant proliferating trichilemmal tumour with recurrence, in an elderly male at an unusual site.

\section{CASE DETAILS :}

A 79 years old man presented with a mass over the sternum since 6 months which was insidious in onset and gradually progressive in size. There was no history of trauma or any other comorbidities. The lesion was excised and sent for histopathological study. Grossly the lesion was skin covered soft tissue nodule measuring $1.7 \times 1 \times 1 \mathrm{~cm}$. Microscopy showed an infiltrating dermal tumour arranged in lobules, (Figure1shown in Annexure) nests and sheets composed of round to polygonal cells exhibiting moderate pleomorphism with vesicular nuclei and prominent nucleoli. Centre of lobules showed abrupt keratinisation (Figure 2 shown in Annexure). Few individual cell keratinisation were also noted. There were 5-7 mitotic figures per high power field (Figure 3 shown in Annexure). Based on the above histologic features, a diagnosis of malignant proliferating trichilemmal tumour was made. One and half years later he presented with a similar lesion at the same site. Grossly, the second lesion was skin covered mass measuring $4 \times 3 \times 3 \mathrm{~cm}$ with firm grey white cut surface (Figure 4) and with the same microscopic features as the previous lesion.

\section{DISCUSSION :}

Proliferating trichilemmal tumours (PTT) are well-circumscribed dermal or subcutaneous neoplasms with squamoid cytologic features and trichilemmal-type of keratinization. This tumour has many synonyms like proliferating trichilemmal cyst, pilar tumour of the scalp, giant hair matrix tumour, invasive hair matrix tumour, hydatidiform keratinous cyst, proliferating epidermoid cyst and trichochlamydocarcinoma, [2]. There are three classes into which these tumours have been classified: benign, locally aggressive, and malignant [3]. It was Headington [4] who proposed the term "malignant proliferating trichilemmal cyst" for the Proliferating trichilemmal cyst with malignant transformation. But due to rarity, inconsistencies in nomenclature and misclassification as squamous cell carcinoma, the real incidence of a malignant proliferating trichilemmal cyst is unknown.

Proliferating trichilemmal tumours are more commonly seen in women (84\%) in the age range of 27 to 83 years with the maximum incidence in the sixth and seventh decades of life [5]. Lanugo hair follicles of the bald scalp and follicles of other areas devoid of non-terminal hair are unlikely to produce these types of tumours. So pilar tumours are uncommon in the bald scalp and are commonly seen in areas with excess hair growth [6]. About ninety percent of tumours occur on the scalp; but they have also been found on the forehead, nose, elbow, wrist, chest, back, abdomen, buttocks, 
mons pubis and vulva [2, 7]. Malignant Proliferating trichilemmal tumours (MPTTs) have a similar histologic picture as of squamous cell carcinoma (SCC) thus challenging the histopathologist. SCCs are usually preceded by precursor epidermal lesions like actinic keratosis while MPTTs are generally not. The key microscopic feature to distinguish MPTTs from SCCs is the abrupt (trichilemmal type) keratinization in the former. Also, the lobular arrangement of tumour cells is more often seen in MPTTs than in SCCs [8]. Furthermore, the positivity of immunohistochemical markers CD34 and calretinin support origin from outer root sheath.

\section{CONCLUSION :}

The rarity of Malignant proliferating trichilemmal tumours, its aggressive course, and its tendency to recur and metastasize more frequently than squamous cell carcinoma [8, 9] calls for an accurate diagnosis of this entity. Treatment involves surgical excision of the lesion with wide margins, followed by careful follow up of the patient.

\section{REFERENCES :}

[1] Wilson-Jones E. Proliferating epidermoid cysts. Arch Dermatol. 1966;94:1-9.

[2] Brownstein M H, Arluk D J. Proliferating trichelemmal cyst: A simulant of squamous cell carcinoma. Cancer. 1981;48:1207-14.

[3] Ye J, Nappi O, Swanson P E, Patterson JW, Wick M R. Proliferating pilar tumours: A clinicopathologic study of 76 cases with a proposal for definition of benign and malignant variants. Am J Clin Pathol. 2004;122:566-74.

[4] Headington J T. Tumors of the hair follicle: A review. Am J Pathol. 1976;85:480-514.

[5] Janitz J, Wiedersberg H. Trichilemmal pilar tumors. Cancer. 1980;45:1594-7.

[6] Saida T, Oohara K, Hori Y, Tsuhiya S. Development of a malignant proliferating trichilemmal cyst in a patient with multiple trichilemmal cysts. Dermatologica. 1983;166:203-8.

[7] Markal N, Kurtay A, Velidedeoglu H, Hucumenoglu S. Malignant transformation of a giant proliferating trichilemmal tumour of the scalp: Patient report and literature review. Ann Plast Surg. 1998;41:314-6.

[8] Rao S, Ramakrishnan R, Kamakshi D, Chakravarthi S, Sundaram S, Prathiba D. Malignant proliferating trichilemmal tumour presenting early in life: An uncommon feature. J Cutan Aesthet Surg 2011;4:51-5.

[9] Yotsuyangi T, Urushidate S, Yokoi K, Sawada Y. A malignant proliferating trichilemmal tumour, simulating squamous cell carcinoma. Eur J Plast Surg. 1997;20:320-2. 
International Journal of Health Sciences and Pharmacy (IJHSP), ISSN: 2581-6411, Vol. 4, No. 1, June 2020.

\section{Annexure :}

\section{Photographs :}

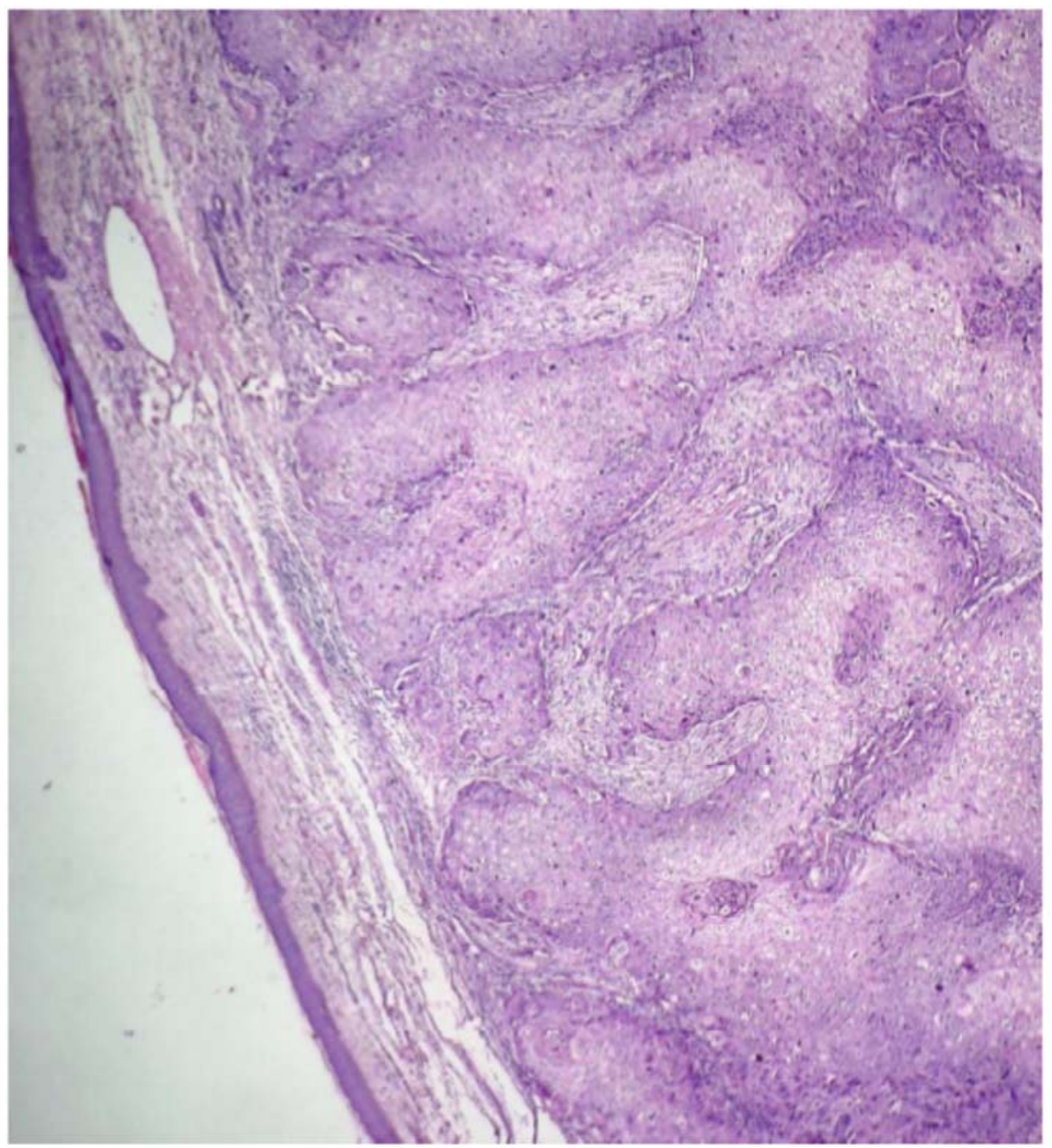

Fig. 1 : Unremarkable epidermis with a dermal tumour arranged in lobules (H\&E, 40x) 
International Journal of Health Sciences and Pharmacy (IJHSP), ISSN: 2581-6411, Vol. 4, No. 1, June 2020.

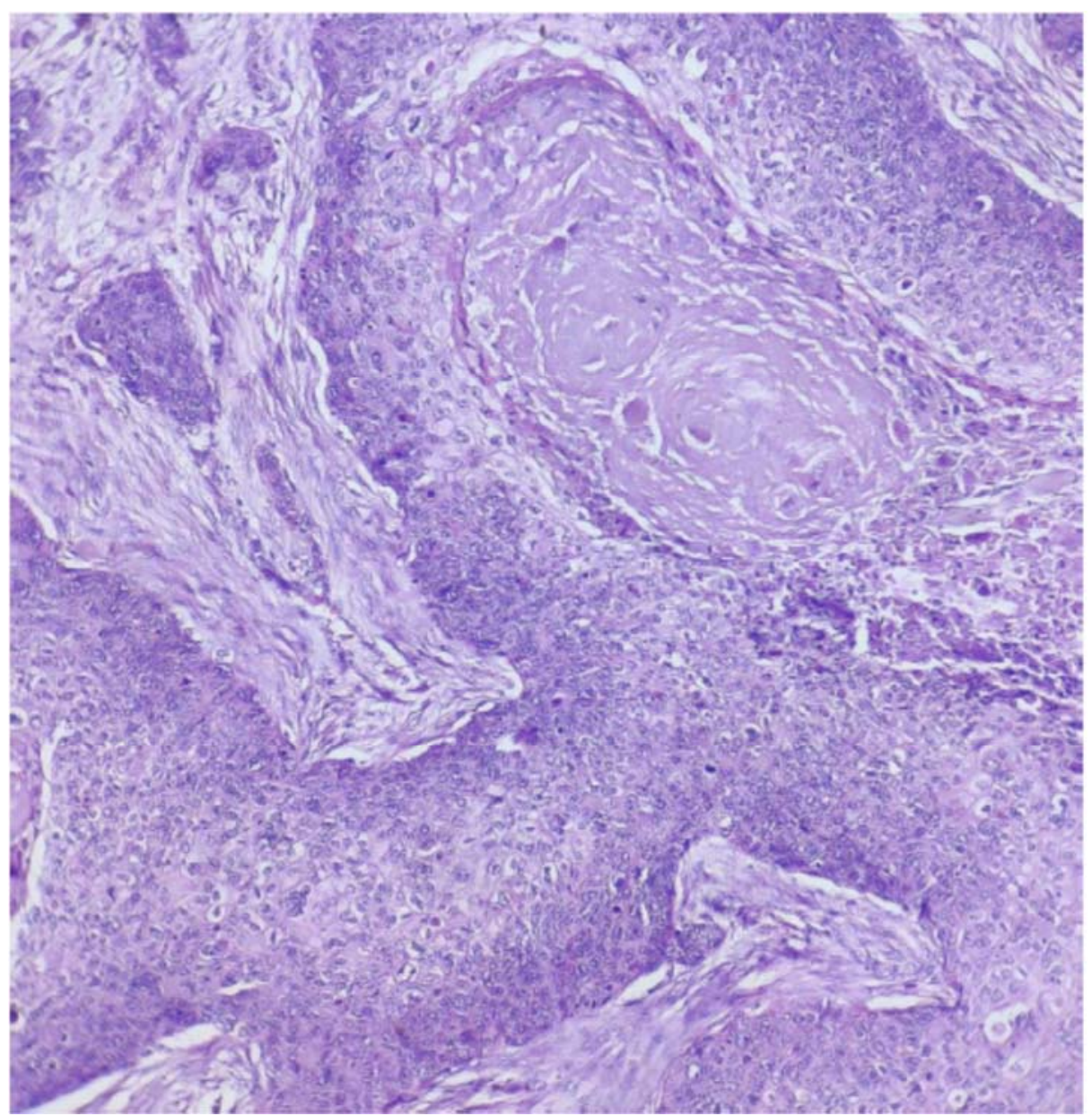

Fig. 2 : Tumour lobules with abrupt keratinisation (H\&E,100x) 


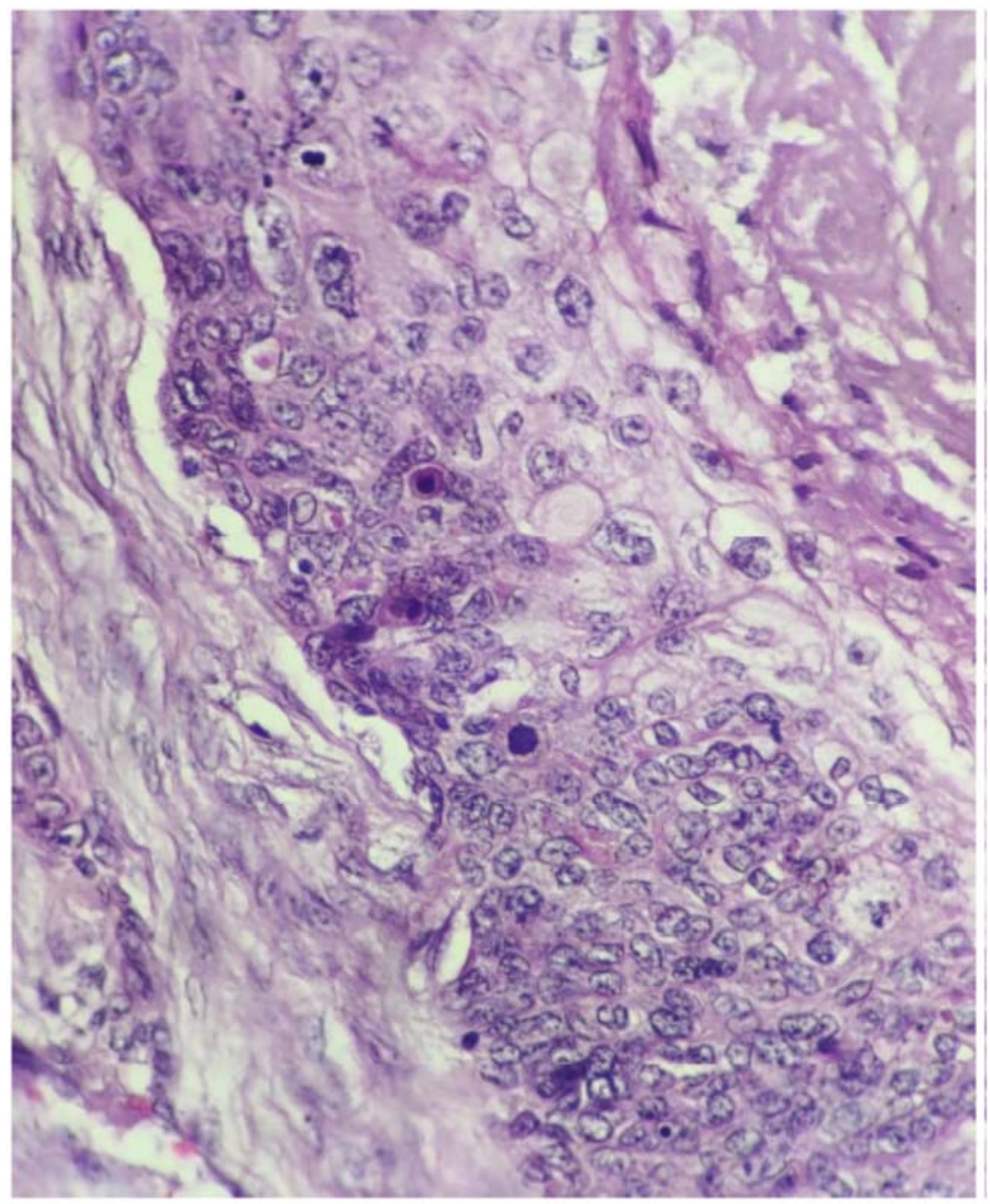

Fig. 3: Pleomorphic tumour cells with atypical mitotic figures (H\&E, 400x) 


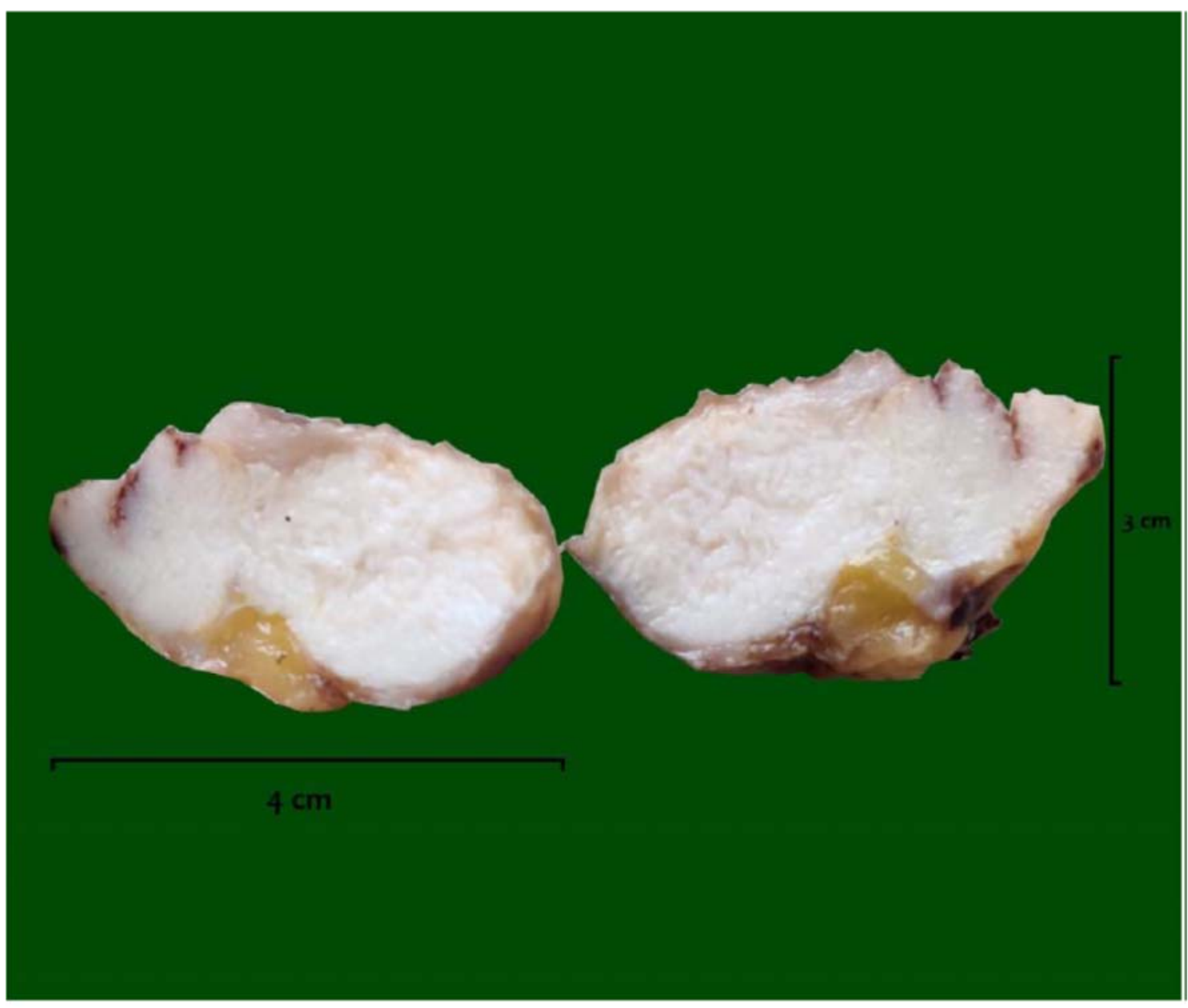

Fig. 4 : Gross appearance of the tumour showing grey white firm cut surface 